\title{
Yield Potential Evaluation in Chickpea Genotypes under Late Terminal Drought in Relation to the Length of Reproductive Stage
}

\author{
Nezar H. Samarah ${ }^{1 *}$, Nasri Haddad ${ }^{2}$, Ahmad M. Alqudah ${ }^{1}$ \\ ${ }^{1}$ Department of Crop Production, Jordan University of Science and Technology \\ P.O. Box 3030, Irbid 22110, Jordan \\ ${ }^{2}$ Department of Horticulture and Crop Science, University of Jordan
}

Amman, Jordan

Received: 15 February 2009. Accepted: 4 September 2009.

\begin{abstract}
Chickpea grown in the semiarid Mediterranean environments of West Asia and North Africa may experience an extended late-drought stress. The objective of this experiment was to evaluate seed dry weight accumulation, reproductive growth duration, and seed yield in five chickpea genotypes in order to identify those under drought stress. Chickpea plants were exposed to two irrigation treatments (from flowering to seed physiological maturity): 1) Irrigation; 2) non-irrigation (rainfed) treatment. Seed dry weight and moisture content, seed yield and yield components, and reproductive growth duration [as defined from flowering to physiological maturity (yellow pods)] were measured. Seeds from plants grown under non-irrigation (rainfed) treatment reached their maximum dry weight and minimum seed moisture content earlier than those from plants grown under irrigation treatment, indicating that chickpea had shorter reproductive growth duration and faster maturity under late-terminal drought (rainfed). The non-irrigation treatment decreased seed yield by $49-54 \%$ as compared with the irrigation, except for Flip $97-99$ (10\% reduction only). Seed yield was positively correlated with reproductive growth duration. The genotype DZ 10-11 had the highest reproductive growth duration and seed yield under irrigation. Late drought stress (non-irrigation) was detrimental to all genotypes. To maximize seed yield of chickpea, late-terminal drought stress should be avoided.
\end{abstract}

Key words: Late-drought, seed filling duration, seed dry weight, seed moisture content.

\section{Introduction}

Pulse grains are an essential part of the daily diet for people in many developing countries where a larger proportion of the population cannot afford animal products (Mike, 1988). Chickpea (Cicer arietinum L.) is the second most important pulse crop in the world, grown over 42 countries in South Asia, West Asia, North Africa, East Africa, Southern Europe, North and South America, Australia (Singh, 1997). Besides its role in reducing the gap in protein nutrition of cereal-dominated diets in developing countries, it provides high quality feed for livestock. Moreover, as a legume, its cultivation fits well in cereal-cereal or cereal-fallow rotation systems where it contributes to the system sustainability and reduces the need for nitrogen fertilization.

Chickpeas growing area and production in Jordan are declining due to the low yield and low income from chickpea cultivation (Haddad and Snobar, 1990). The low yield is a result of the existing chickpea cultivars, which have a low tolerance to soil water deficit usually.

Drought is one of the most important factors which limit the productivity of rainfed chickpea in the Mediterranean environments of West Asia and North Africa (Smith and Harris, 1981). Chickpeas yield losses due to inadequate soil moisture availability, varies between 36 and $42 \%$ depending on geographic location and climatic condition during the crop season (Saxena et al., 1993).

\footnotetext{
* Corresponding Author: Tel. +962 27201000 Ext, 22055. E-mail address: nsamarah@just.edu.jo
} 
The type of drought stress, which affects cool-season food legumes, including chickpeas are: an intermittent drought stress caused by breaks in winter rainfall, and terminal drought stress, resulting from receding soil moisture. In Jordan, terminal drought is more stressful than the intermittent drought, due to the low and irregular rainfall occurring during April and May, which affect spring-sown chickpeas.

One mechanism of adaptation to late soil water deficit adopted by plants is drought escape, which consist in anticipating pod ripening before the onset of the severe drought (Saxena et al., 1993). Indeed, according to Farah et al. (1988), flowering is the most sensitive stage of growing season to drought stress in many pulses.

In the Mediterranean environment, the most gain in yield and yield stability are likely to come from tailoring crop duration to the limit of available soil moisture in the growing season, thus exploiting the drought escape trait. However, a negative correlation between days-toflowering and yield in rainfed chickpeas was found (Saxena, 1987). Breeding for early flowering types will lead, therefore, to cultivars with short seed filling duration which, however, may suffer a yield reduction in years when soil moisture condition are above average. It is, therefore, important to investigate the possibility of identifying chickpea genotypes early in flowering but with a prolonged seed filling period as well as a high rate of seed filling, that will allow yield stability and can escape the late season soil moisture stress.

The objective of this experiment was to evaluate seed dry weight accumulation, reproductive growth duration, and seed yield in five chickpea genotypes, with the aim of identifying those with a better capacity to produce, fill and ripe the seeds under terminatal drought stress conditions.

\section{Materials and methods}

Field experiment was conducted at the Experiment Station of Jordan University of Science and Technology (JUST), Irbid, Jordan in growing season 2003/2004. Five chickpea genotypes were evaluated under late-terminal drought stress imposed from flowering to seed physiological maturity (yellow pods).
Three Kabuli and two Desi genotypes were used for the experiment. The Kabuli genotypes were: Flip 93-255, Flip 97-99 provided by the International Center for Agricultural Research in the Dry Areas (ICARDA), and Jubeiha 3, a released tall type variety in Jordan. The Desi genotypes were: DZ 10-11 and DZ 10-92 received from Ethiopia (Ethiopian Agricultural Research Organization). The genotypes were sown the $17^{\text {th }}$ of December.

Before sowing, $100 \mathrm{~kg} \mathrm{ha}^{-1}$ of diammonium phosphate were distributed in field. Twenty seeds of each cultivar were sown in $3 \mathrm{~m}$ lines with $25-\mathrm{cm}$ apart at a depth of $10 \mathrm{~cm}$. Plants were irrigated once a week $(7 \mathrm{~mm})$ to prevent early drought stress. From the $11^{\text {th }}$ of April 2004 onward, plants were exposed to two irrigated regimes: 1) irrigation and 2) non-irrigated (terminal drought stress). In irrigated treatment water was distributed once a week $(7 \mathrm{~mm})$ until pod ripening.

Maximum and minimum temperature, relative air humidity and rainfall were recorded during the growing season 2003/2004 (Fig. 1). The location is considered as a typical a semiarid Mediterranean area with total annual rainfall of $195 \mathrm{~mm}$ in December, January, February, and March whilst few rainy events occurred during April and May. The highest maximum and minimum relative humidity were recorded during December, 2003 to March, 2004. The lowest values of maximum and minimum temperature were recorded during December, 2003, January and February, 2004, then temperature increased during March, April and May up to a maximum.

\subsection{Seed dry weight, seed moisture content, and reproductive growth duration}

Flowers from 5 plants were tagged to study seed development and seed filling rate and duration. Ten pods from selected flowers were harvested $7,14,21,28,35$ days after flowering and at the end of the seed maturity period (56-77 days) after flowering. Seed moisture and dry weight were measured at each harvest time to determine seed filling rate. Seed moisture was measured by weighing the seeds immediately after harvest and after oven drying at $70^{\circ} \mathrm{C}$ for $24 \mathrm{~h}$. Percentage of seed moisture was calculated as a difference between seed fresh weight and seed dry weight divided by seed fresh weight (fresh weight basis) according to ISTA Rules (1993). 

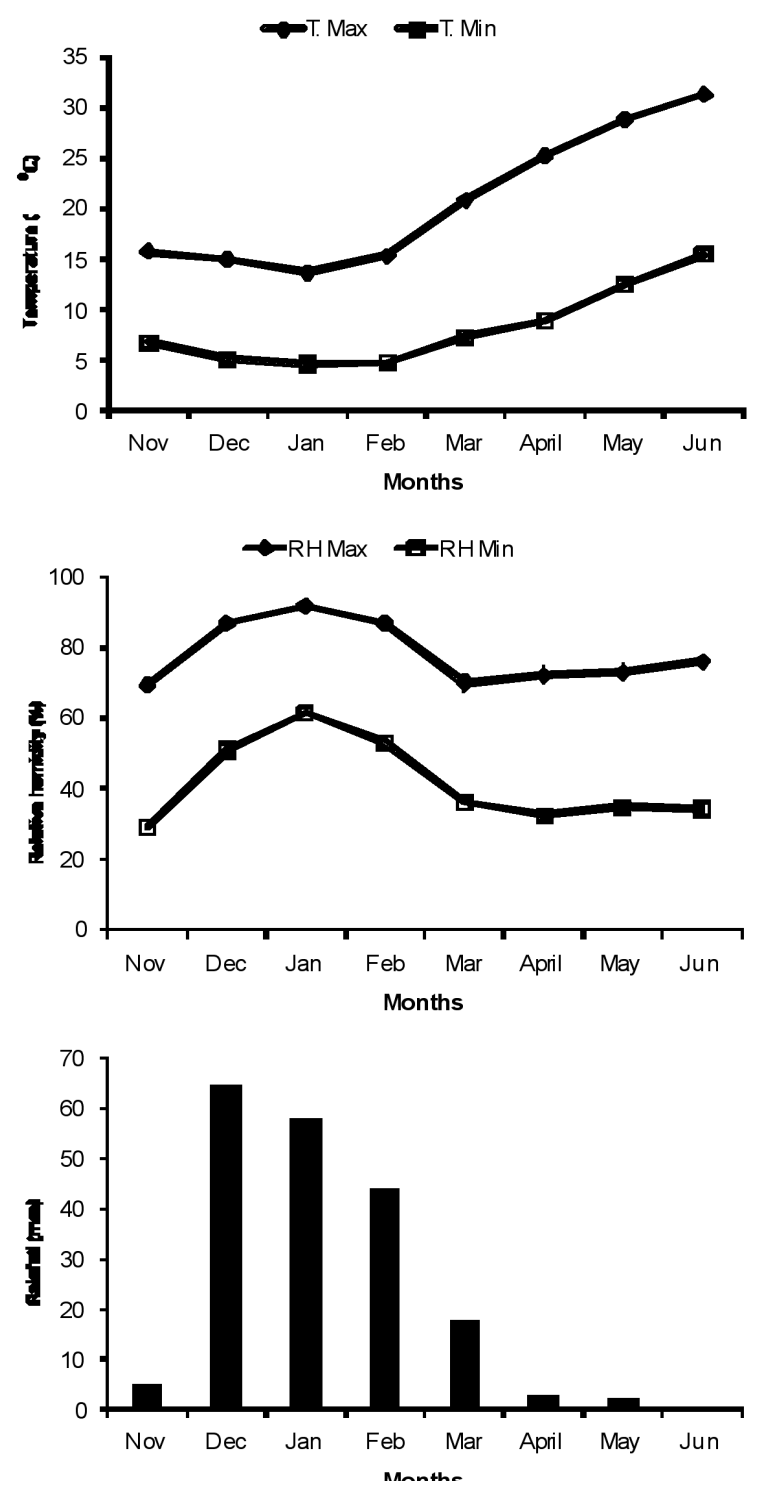

Figure 1. Maximum and minimum air temperature, air relative humidity and rainfall during the growing season $2003 / 2004$ at JUST.

Reproductive growth duration was determined and defined as the period from flowering to seed physiological maturity (the pods turned to yellow).

\subsection{Yield and yield components}

At maturity, 5 plants were sampled randomly and measured for seed yield, and yield components. Yield components (number of seed, pod, and weight per 100 seeds) are reported as number per plant.

\subsection{Experimental design and statistical analysis}

The experiment was conducted in a split-plot experimental design with three replications assigning the irrigation treatment to the main plot and the genotype to sub-plot. The main-plot treatment was the irrigation and the sub-plot treatments were the genotypes. Analysis of variance for the collected data was conducted using the general linear model procedure of SAS (SAS Institute, 1996). Fisher's Least Significant Difference (LSD) was used for mean comparisons among treatments, when the $F$-test was significant $(P=0.05)$.

\section{Results and discussion}

\subsection{Seed dry weight and moisture content}

Seed dry weight and moisture content of five chickpea genotypes grown under irrigation and non-irrigation conditions during the reproductive stages (from flowering to seed maturity) are shown in Figure 2. In general, seeds from plants grown under non-irrigation treatment reached their maximum dry weight earlier (4-21 days) than those from plants grown under irrigation treatment. This pattern of faster seed filling growth rate under non-irrigation treatment was most pronounced in the genotype DZ 10-11. Seed moisture decreased as seed matured, reaching minimum value earlier in seeds from plants grown under non-irrigation treatment. These results indicate that the seeds from the plants grown under non-irrigation treatment during seed filling accumulated the dry weight at faster rate, and matured earlier than those from plants grown under irrigation treatment. Indeed, late drought stress has been demonstrated to shorten the length of growing season or to accelerate ripening in chickpea (Singh, 1991). Understanding the detailed pattern of water use in relation to crop phenology and assimilate partitioning into the seeds is required to achieve maximum growth and yield in chickpea (Anwar et al., 2003).

3.2 Seed yield, yield components, and reproductive growth duration

Data of seed yield and yield components are shown in Tables 1 and 2 . The genotype $\mathrm{x}$ treatment interaction was not significant for seed number and seed dry weight, whereas the two 

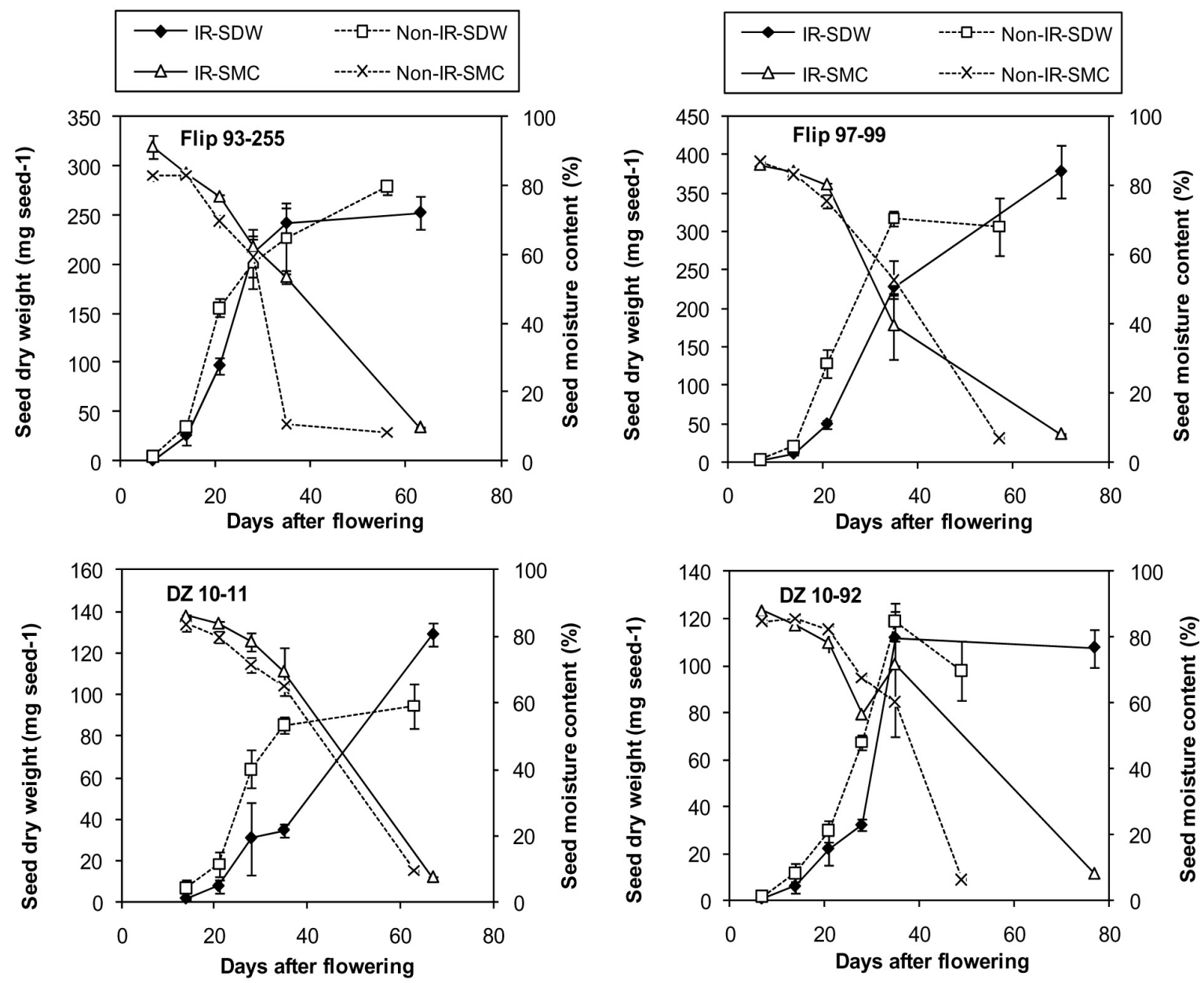

Figure 2. Seed dry weight (SDW) and moisture content (SMC) on a fresh weight basis for five chickpea genotypes exposed to two irrigation treatments (from flowering to seed physiological maturity): 1) Irrigation (IR); 2) non-irrigation (rainfed) (Non-IR) treatment. Bars indicate the standard error of the mean.

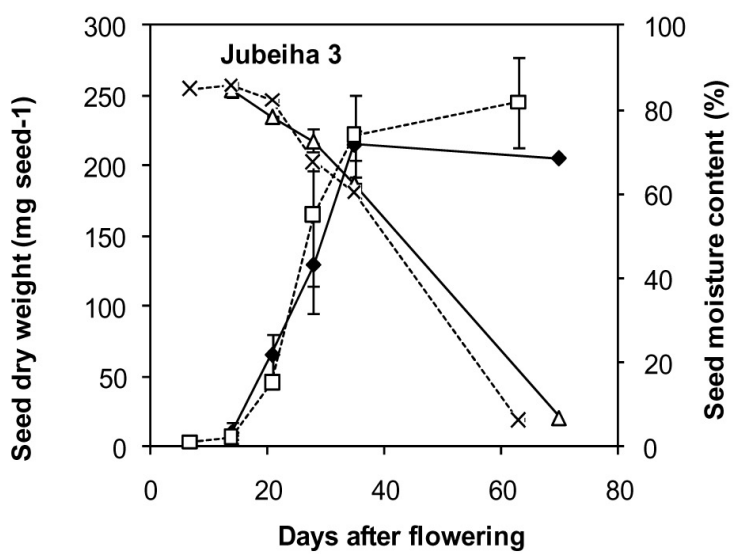

experimental factors significantly interacted in pod number, seed yield, and reproductive growth duration. Plants grown under irrigation treatment had significantly higher seed number and seed dry weight than those grown under non-irrigation treatment (Tab. 1). Among all genotypes, DZ 10-11 had had the highest one seed number. The genotype Flip 97-99 had the

highest 100 -seed weight, whereas the genotype DZ 10-11 and DZ 10-92 had the lowest. There was no significant difference in 100 -seed weight between Flip 93-255 and Jubeiha 3. A highly significant $(\mathrm{P}<0.001)$ interacting effects of irrigation, sowing date and cultivar on water use efficiency and seed yield has been reported in chickpea (Anwar et al., 2003). 
Table 1. Seed number and 100-seed weight of five chickpea genotypes grown under two irrigation treatments during reproductive growth stages (from flowering to seed physiological maturity).

\begin{tabular}{lcc}
\hline & Seed Number & 100-Seed Weight \\
\cline { 2 - 3 } & No. plant ${ }^{-1}$ & mg seed $^{-1}$ \\
\hline Treatments & & \\
Irrigation & $200 \mathrm{a} \dagger$ & $23.9 \mathrm{a}$ \\
Non-irrigation & $125 \mathrm{~b}$ & $21.7 \mathrm{~b}$ \\
& & \\
Genotypes & & \\
Flip 93-255 & $135 \mathrm{~b}$ & $26.4 \mathrm{~b}$ \\
Flip 97-99 & $106 \mathrm{~b}$ & $32.7 \mathrm{a}$ \\
DZ 10-11 & $320 \mathrm{a}$ & $14.6 \mathrm{c}$ \\
DZ 10-92 & $130 \mathrm{~b}$ & $13.0 \mathrm{c}$ \\
Jubeiha 3 & $123 \mathrm{~b}$ & $27.7 \mathrm{~b}$ \\
& & \\
Treatments (T) & $* * *$ & $*$ \\
Genotypes (G) & $* * *$ & $\mathrm{~ns}$ \\
T $*$ G & $\mathrm{ns}$ & \\
\hline
\end{tabular}

$\dagger$ Values within the same column for treatments or cultivars followed by the same letter are not significantly different according to $\operatorname{LSD}(P=0.05)$

*** Significant at $P=0.001$; ns: not significant.

In all genotypes, plants grown under non-irrigation treatment had lower pod number, seed yield, and reproductive growth duration, but the magnitude of this reduction varied with genotypes (Tab. 2). In particular, under rainfed conditions (non-irrigated treatment) plant produced the $56,20,40,39$, and $43 \%$ less pods than those irrigated, in Flip 93-255, Flip 97-99, DZ
10-11, DZ 10-92, and Jubeiha 3, respectively. Soil water deficit during late ripening (non-irrigated treatment) determined a seed yield decrease ranging from 49 to $54 \%$ except in Flip 97-99, where seed yield reduction was negligible $(10 \%)$. These results are in agreement with literature, which reports yield increase of $65 \%$ (Oweis et al., 2004) and 10\% (Zhang et al., $2000)$ in chickpea under full supplementary irrigation, as compared to that under rainfed conditions. However, the $2 / 3$ supplementary irrigation level has been demonstrated to make optimum the water use efficiency (Oweis et al., 2004). Moreover, a limited supplemental irrigation has been found to increase and stabilize the productivity of spring-sown chickpea (Soltani et al., 2001). Indeed, a significant correlation $(\mathrm{P}<$ $0.001)$ between water use and seed yield of chickpea $\left(\mathrm{R}^{2}=0.75\right)$ (Anwar et al., 2003) has been observed. In the present study, the reproductive growth duration was greatly reduced (21 and 12 days) under rainfed conditions in genotypes DZ 10-11 and DZ 10-92, respectively; it was less affected (by approximately 15\%) in remaining genotypes.

The genotype DZ 10-11 produced the highest pod number and seed yield, and the longest reproductive growth duration when irrigated; conversely genotypes Flip 97-99 and DZ 10-92 produced the lowest pod number and seed yield. Under non-irrigation conditions, DZ 10-

Table 2. Pod number, seed yield, and reproductive growth duration of five chickpea genotypes grown under two irrigation treatments during reproductive growth stages (from flowering to seed maturity).

\begin{tabular}{|c|c|c|c|c|c|c|}
\hline \multirow[t]{3}{*}{ Treatments } & \multicolumn{2}{|c|}{ Pod Number } & \multicolumn{2}{|c|}{ Seed Yield } & \multicolumn{2}{|c|}{ Reproductive Growth Duration } \\
\hline & IR & Non-IR & IR & Non-IR & IR & Non-IR \\
\hline & \multicolumn{2}{|c|}{ No.plant $^{-1}$} & \multicolumn{2}{|c|}{ g plant ${ }^{-1}$} & \multicolumn{2}{|c|}{ Days } \\
\hline Genotypes & & & & & & \\
\hline Flip 93-255 & $156 b \dagger A \ddagger$ & 100bB & $49.1 \mathrm{bA}$ & $25.1 \mathrm{aB}$ & $40 \mathrm{cA}$ & $35 \mathrm{~dB}$ \\
\hline Flip 97-99 & $108 \mathrm{cdA}$ & 86bB & $36.1 \mathrm{cA}$ & $32.6 \mathrm{aB}$ & $48 \mathrm{bA}$ & $41 \mathrm{bB}$ \\
\hline DZ 10-11 & $318 \mathrm{aA}$ & $190 \mathrm{aB}$ & $65.6 \mathrm{aA}$ & $29.7 \mathrm{aB}$ & $59 \mathrm{aA}$ & $38 \mathrm{cB}$ \\
\hline DZ 10-92 & $124 \mathrm{bcA}$ & $76 \mathrm{bB}$ & $23.0 \mathrm{dA}$ & $10.9 \mathrm{bB}$ & $48 \mathrm{bA}$ & $36 \mathrm{cB}$ \\
\hline Jubeiha 3 & $151 \mathrm{bA}$ & $86 \mathrm{bB}$ & $45.6 \mathrm{bcA}$ & $23.0 \mathrm{aB}$ & $49 \mathrm{bA}$ & $45 \mathrm{aB}$ \\
\hline Treatments $(\mathrm{T})$ & \multicolumn{2}{|c|}{$* * *$} & \multicolumn{2}{|c|}{$* * *$} & \multicolumn{2}{|c|}{$* * *$} \\
\hline Genotypes (G) & \multicolumn{2}{|c|}{$* * *$} & \multicolumn{2}{|c|}{$* * *$} & \multicolumn{2}{|c|}{$* * *$} \\
\hline $\mathrm{T} * \mathrm{G}$ & \multicolumn{2}{|c|}{$*$} & \multicolumn{2}{|c|}{$*$} & \multicolumn{2}{|c|}{$* * *$} \\
\hline
\end{tabular}

$\dagger$ Values within the same column for cultivars followed by the same small letters are not significantly different according to LSD $(P=0.05)$.

\$ Values within the same row for treatments followed by the same capital letters are not significantly different according to LSD $(P=0.05)$.

*, *** Significant at $P=0.05$ and 0.001 , respectively; ns: not significant. 


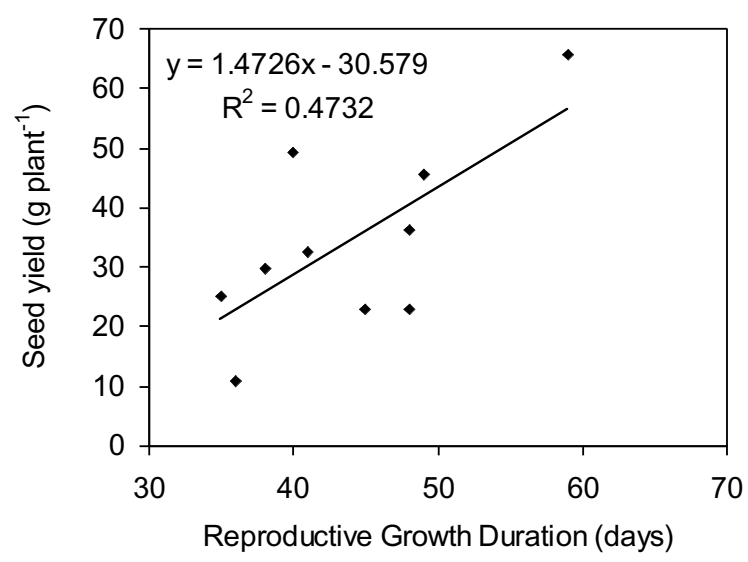

Figure 3. Relationship between reproductive growth duration and seed yield of chickpea.

92 produced less than the other genotypes. Flip 93-255, Flip 97-99, DZ 10-11 and Jubeiha 3 did not significantly differ in seed yield, although DZ 10-11 produced a higher number of pods. Among genotypes, Flip 93-255 was the earliest under both experimental conditions.

Although previous studies have shown an increase in productivity of chickpea by supplementary irrigation supplied throughout the growing season (Oweis et al., 2004; Zhang et al., 2000; Anwar et al., 2003), few studies have related seed yield of chickpea under late-drought stress with plant reproductive growth duration. In the present study, a positive relationship between reproductive growth duration and seed yield was observed (Fig. 3). Previous works have demonstrated how winter-sown chickpea is less likely to face drought during flowering and grain filling than spring-sown chickpea because the earlier crop growth of winter-sown chickpea results in a higher leaf area and plant growth so allowing earlier maturity and escape from the later drought (Oweis et al., 2004). Some researchers (Jadhav et al., 1997) suggested that the most sensitive growth stage of chickpea to drought is flowering, while some others (Ravi et al., 1998; Reddy and Ahlawat, 1998) demonstrated that the seed filling is the critical time for irrigation. Chickpea yield is reported to be more responsive to irrigation when plants are irrigated at flowering and pod filling (Malhotra et al., 1997). In the present study, late-drought stress (rainfed) was very detrimental to seed yield and yield components and supplementary irrigation increased grain yield and yield per plant by extending the reproductive growth duration.

\section{Conclusion}

Seeds from plants grown under non-irrigation (rainfed) treatment reached their maximum dry weight and minimum seed moisture content earlier than those from plants grown under irrigation treatment, indicating a shortening in the reproductive growth duration and a faster maturity under rainfed conditions. The reduction in seed yield due to late water stress ranged from 49-54\% except in Flip 97-99 whose yield was the $10 \%$ reduced under dry conditions. Seed yield was positively correlated with the reproductive growth duration. The genotype DZ 10-11 had the longest reproductive growth and highest seed yield under irrigation. Late-terminal drought stress (non-irrigation) was detrimental to all genotypes. Therefore, to maximize seed yield of chickpea, late-terminal drought stress should be avoided.

\section{Acknowledgements}

This project is financially supported by the Deanship of Research at Jordan University of Science and Technology. Thanks also extend for Eng. Maha Al-Mahasneh for her assistant in field.

\section{References}

Anwar M.R., Mckenzie B.A., Hill G.D. 2003. Water-use efficiency and the effect of water deficits on crop growth and yield of Kabuli chickpea (Cicer arietinum L.) in a cool-temperate subhumid climate. Journal of Agricultural Science, 141: 285-301.

Haddad N.I., Snobar S. 1990. The role of legume in the farming in Jordan. In: Osman A., Ibrahim A.H., Johnes M.A. (eds.): The role of legumes in the farming systems of the Mediterranean areas. ICARDA, Aleppo, Syria.

ISTA. 1993. International rules for seed testing. Seed Science and Technology 21, Supplement. Int. Seed Testing Assoc, Zurich, Switzerland.

Jadhav J.D., Shewale M.R., Mokashi D.D., Gaikwad C.B., Patil J.D. 1997. Crop coefficients and actual evapotranspiration of gram (Cicer arietinum) grown in lysimeter. Indian Journal of Agricultural Sciences, 67:33-35. 
Farah S.M., Arar A., Miller D.E. 1988. Water requirements and the irrigation management of pea, lentil, faba bean and chickpea crops. In: Summerfield R.J. (ed.): World crops. Cool season food legumes, The Netherlands, Kluwer.

Malhotra R.S., Singh K.B., Saxena M.C. 1997. Effect of irrigation on winter-sown chickpea in a Mediterranean environment. Journal Agronomy and Crop Science, 178:237-243.

Mike A. 1988. Genetic improvement of food legumes in developing countries by mutation induction. In: Summerfield R.J. (ed.): Cool season food legumes. Klumar, Netherlands.

Oweis T., Hachumb A., Pala M. 2004. Water use efficiency of winter-sown chickpea under supplemental irrigation in a Mediterranean environment. Agricultural Water Management, 66:163-179.

Ravi N., Sharma H.M., Singh R.P., Nandan R. 1998. Response of late-sown chickpea to irrigation and foliar nutrition in calcareous soil. Journal of Applied Biology, 8:5-8.

Reddy N.N., Ahlawat I.S. 1998. Response of chickpea (Cicer arietinum) genotypes to irrigation and fertilizers under late-sown conditions. Indian Journal of Agronomy, 43:95-101.

SAS Institute. 1996. The SAS System for Windows 6.12 . SAS Inst., Cary, NC.
Saxena N.P. 1987. Screening for adaptation to drought: Case studies with chickpea and pigeonpea. In: Adaptation of chickpea and pigeonpea to abiotic stresses. Proc. Consultants' workshop, Patancheru, India, December 1984. Patancheru, India: ICRISAT.

Saxena N.P., Johansen C., Saxena M.C., Slim S.N. 1993. Selection for drought and salinity tolerance in coolseason food legume. In: Singh K.B., Saxena M.C. (eds.): Breeding for stress tolerance in cool-season food legumes. John Wiley and Sons, New York.

Singh K.B. 1997. Chickpea (Cicer arietinum L.). Field Crops research, 53:161-170.

Singh P. 1991. Influence of water deficits on phenology, growth and dry matter allocation in chickpea (Cicer arietinum). Field Crops Research, 28:1-15.

Smith R.C.G., Harris H.C. 1981. Environmental resources and restrains to agricultural production in the Mediterranean type environment. In: Monteith J., Webb C. (eds.): Soil water and nitrogen. The Hague, The Netherlands: Martinus Nijhoff/Junk.

Soltani A., Khooie F.R., Ghassemi-Golezni K., Moghaddam M. 2001. A simulation study of chickpea crop response to limited irrigation in a semiarid environment. Agric. Water Manage, 49:225-237.

Zhang H., Pala M., Oweis T., Harris T.H. 2000. Water use and water use efficiency of chickpea and lentil in a Mediterranean environment. Aust. J. Agric. Res., 51:295-304. 